
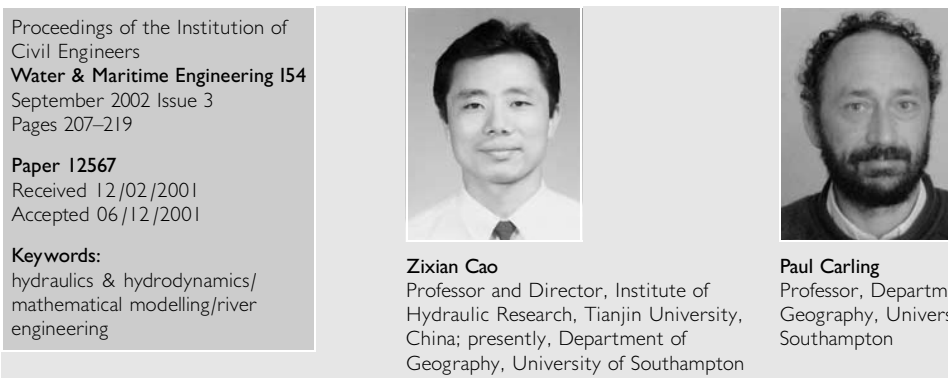

\title{
Mathematical modelling of alluvial rivers: reality and myth. Part I: General review
}

\section{Z. Cao and P. A. Carling}

Mathematical modelling fluvial flow, sediment transport and morphological evolution started half a century ago and, to date, a variety of mathematical models have been developed and are in widespread use. However, the quality of mathematical river modelling remains uncertain because of: (a) poor assumptions in model formulations; (b) simplified numerical solution procedure; (c) the implementation of sediment relationships of questionable validity; and ( $d$ ) the problematic use of model calibration and verification as assertions of model veracity. An overview of mathematical models for alluvial rivers is provided in this and the companion paper 'Part 2: Special issues'. This paper is the first part, providing a general review of mathematical river models. The issues addressed comprise what have been obvious since the very beginning of mathematical river modelling and are still open, and also the pertinent components that pose challenges to model developers and end-users pursuing refined modelling practice. In particular the simplified mass conservation equations, asynchronous solution procedures, sediment transport functions, movable-bed resistance, numerical difficulty for strong hyperbolic equations, and representation of movable and complex geometry are discussed. A test example is provided to demonstrate the impacts of simplified mass conservation equations and an asynchronous solution procedure in comparison with those of largely tuned friction factors. It is concluded that mathematical models for fluvial flowsediment-morphology systems are far from being mature, and that considerable expertise, physical insight and experience are vital for meaningful solutions to be acquired and for the limitations of modelling outputs to be properly identified, interpreted and assessed.

\section{NOTATION}

C mean volumetric sediment concentration

$f \quad$ Darcy-Weisbach friction factor

$f_{0} \quad$ Darcy-Weisbach friction factor under initial condition

h flow depth

$L_{1} \quad$ normalised $L_{1}$-norm between changes of bed elevation

$R_{\mathrm{T}} \quad$ relative time-scale of bed deformation

$t \quad$ time

$\boldsymbol{U}$ mean velocity

$\boldsymbol{w} \quad$ sediment settling velocity $x$ $Y_{\text {nor }}$ $\Delta Y$ streamwise coordinate normalised change of bed elevation change of bed elevation

\section{INTRODUCTION}

The ability to make accurate calculations of fluvial flow, sediment transport, the associated morphological evolution processes and water quality is vital in a period when the concern over the river environment and the influence of human intervention is increasing. The interaction between sediment and turbulent flow is of fundamental interest in the field of two-phase flow, and modelling the strongly coupled flowsediment-morphology system provides a problem of considerable interest in computational fluid dynamics. Fluvial sediment transport process has been an increasingly important subject in the fields of water resources engineering, hydrology, geographical, geological, and environmental sciences, and more fundamentally fluid dynamics.

The last half a century has seen encouraging progress in the development of physically based mathematical models relevant to such processes due to the advancement in the performance of computers, as can be found in a huge number of publications in the literature. There has been a significant move from comparatively simpler cross-section-averaged one-dimensional (1D) models in the early 1950s and depth-averaged twodimensional (2D) models since the 1980s to full threedimensional (3D) models more recently. To date, mathematical river modelling has become one of the basic tools for engineering planning, design and assessment. It has, since its early stage of development, been evolving towards one of the proactive problem-solving technologies for the river environment.

Refined mathematical modelling of alluvial rivers continues to be one of the major challenges for river scientists and engineers. Because the knowledge of the physics of turbulent flow, sediment transport, and their mutual interaction is far from complete, existing mathematical models have inevitably come with ambiguity due to the underlying assumptions, approximations and, from time to time, ignorance. In contrast to the likely accepted premise that computational hydraulics for fix-bed rivers, based on the traditional Saint-Venant equations, matured prior to 1960 , that for movable-bed rivers with sediment transport and morphological developments remains 
premature. River scientists and engineers do not have full confidence in making reliable and accurate simulations of sediment transport, whilst the users' community is moving towards a position where rapid impact-modelling and decisionmaking are required with decision support models and hydroinformatics tools. Identifying and delimiting the critical issues will lead in time to the development of improved models for alluvial river processes, which will offer the opportunity for better assessment of project risk.

The primary aim of this and the companion paper is to provide an overview of mathematical models for alluvial rivers. It is also intended to spur a wider awareness of the various uncertainties inherent in such models. This paper is the first part of the overview. Firstly a few basic aspects regarding the idealised steady and uniform sediment-carrying flow are highlighted to indicate the limited capability in quantitative description of sediment-laden flows. Then the major issues of mathematical river models are listed, and addressed. A test example is provided to illustrate the considerable impacts of the asynchronous solution procedure and simplified continuity equations. In the companion paper, ${ }^{1}$ several special issues are recalled in detail, which pose the basic impediments to refined mathematical river modelling and merit further fundamental research. These include turbulence closure models with particular emphasis on the role of sediment in modifying turbulence, the bottom boundary conditions for mean flow and sediment, and the calibration and verification/validation methodology widely used in mathematical river modelling. Suggestions are also made that can improve the current mathematical river modelling practice.

\section{THE REALITY WITH IDEALISED STEADY AND UNIFORM FLOW}

An idealised case is the steady and longitudinally uniform water-sediment flow, which is mathematically the simplest to solve. Currently it is impossible to predict this kind of flow with sufficient confidence. Consider the following basic realities.

(a) It is difficult to correctly compute the mean velocity structure along the vertical. Often it is necessary to resort to a modified von Karman coefficient, Prandtl's mixing theory, or the weakly stable stratified flow analogy that was initially proposed for atmospheric boundary layers.

(b) It is difficult to correctly compute the vertical profile of mean suspended sediment concentration. From time to time it is required to tune, for instance, the Rouse parameter to fit concentration profiles to measured data. There is no universal guidance for use in tuning the Rouse parameter. $^{2,3}$

(c) It is difficult to accurately determine the mean flux of sediment exchange between the water column and the bottom sediment surface. It is necessary to use plainly questionable empirical relationships for the flux of bed sediment exchange in order to estimate the sediment discharge carried by the bulk flow. ${ }^{4-6}$

Given the above statement for the idealised sediment-laden flow, it is undoubtedly of critical significance to recognise the basis, capabilities and limitations of current mathematical river models for the generally more complex fluvial water flowsediment-morphology systems.

\section{MAJOR ISSUES OF MATHEMATICAL MODELS FOR ALLUVIAL RIVERS}

Mathematical models of alluvial rivers can be categorised into two types: academic and applied. Academic models often deal with 'how and why' problems, being devoted to the conceptualisation, mathematical formulation, solution (analytical or numerical) and interpretation of the flow, sediment transport, and morphological reaction. Improving the understanding of the mechanism of interaction among water, sediment and morphology is the major purpose of academic models. On the other hand, applied models are entirely concerned with quantitative modelling of the river systems in response to natural changes (such as climate change) and human activities (e.g. construction of dams, bridges and flood control works). The present overview considers applied modelling only. Currently, the most extensively used fluvial models are either 1D or depth-averaged (shallow) 2D, which are built upon traditional hydraulics principles-that is, Saint-Venant equations. In the present overview the $1 \mathrm{D}$ and $2 \mathrm{D}$ models are distinguished from full 3D models based on the complete fluid dynamics equations implemented with a closure module for turbulence. Additionally, consideration is limited to issues directly related to sediment movement. Those issues purely pertinent to single-phase water flows (without sediment) in rivers are only briefly covered, which however must not be construed as irrelevant.

Table 1 lists a number of major issues of applied mathematical models for alluvial rivers that are addressed, and how these are relevant to various models. These issues encompass a variety of perspectives in fluid dynamics, sediment transport mechanics, morphological considerations, computational aspects as well as controversy pertaining to the methodology of model assessment, etc. In Table 1 the various issues are grouped according to these perspectives which are physically related to a wide spectrum of temporal and spatial scales, ranging from turbulence micro-scales to river-reach scales. In the following, several closely interrelated issues are discussed together.

\section{ID AND 2D COMPUTATIONAL HYDRAULICS MODELS}

This section mainly focuses on 1D hydraulic models, while most aspects examined here are pertinent to depth-averaged 2D cases. Based on cross-section-averaged variables, 1D numerical modelling of alluvial rivers has been most widely used in the fields of river training, hydropower generation, flood control and disaster alleviation, water supply, navigation improvement, as well as environment enhancement. HEC-6, ISIS-Sediment, and Mike11 are examples of a number of mathematical river models developed for fluvial water-sediment-morphology systems. The outputs of these models usually include sediment transport rates, changes in bed elevation and amounts of erosion and deposition throughout the river system considered. It has been recognised that $1 \mathrm{D}$ models are appropriate primarily for long-term and long-reach situations, whereas these models have been less successful for local flow-sediment-morphology problems as can be anticipated. Prior studies in this connection have focused on such aspects as flow resistance relations (including parameter identification and optimisation), grain 


\begin{tabular}{|c|c|c|c|}
\hline & \multirow[b]{2}{*}{ Issues } & \multicolumn{2}{|c|}{$\begin{array}{l}\text { Relevance in models } \\
(Y=\text { yes, } N=\text { no })\end{array}$} \\
\hline & & ID and 2D models & 3D models \\
\hline Fluid mechanics & $\begin{array}{l}\text { Saint-Venant equations } \\
\text { Reynolds-averaged Navier-Stokes equations } \\
\text { Resistance/roughness } \\
\text { Turbulence closure models and sediment effects }\end{array}$ & $\begin{array}{l}Y \\
N \\
Y \\
Y\end{array}$ & $\begin{array}{l}N \\
Y \\
Y \\
Y\end{array}$ \\
\hline Sediment transport mechanics & $\begin{array}{l}\text { Equilibrium versus non-equilibrium sediment transport } \\
\text { Sediment transport and entrainment functions } \\
\text { Heterogeneous sediments } \\
\text { Temporal and spatial lags of bed-load transport } \\
\text { Sediment exchange with bottom boundary }\end{array}$ & $\begin{array}{l}Y \\
Y \\
Y \\
Y \\
Y\end{array}$ & $\begin{array}{l}Y \\
Y \\
Y \\
Y \\
Y\end{array}$ \\
\hline Morphological considerations & $\begin{array}{l}\text { Complex river geometry representation } \\
\text { Riverbed mobility implementation } \\
\text { River bank migration }\end{array}$ & $\begin{array}{l}Y \\
Y \\
Y\end{array}$ & $\begin{array}{l}Y \\
Y \\
Y\end{array}$ \\
\hline Computational aspects & $\begin{array}{l}\text { Synchronous versus asynchronous solution procedures } \\
\text { Hyperbolic equations }\end{array}$ & $\begin{array}{l}Y \\
Y\end{array}$ & Y \\
\hline Model assessment & $\begin{array}{l}\text { Calibration } \\
\text { Verification/validation }\end{array}$ & $\begin{array}{l}Y \\
Y\end{array}$ & $\begin{array}{l}Y \\
Y\end{array}$ \\
\hline
\end{tabular}

sorting, non-equilibrium modules, numerical techniques, and effects of vertical distributions. ${ }^{7-16}$ In the present state of the art, it is a common practice to tune the friction factor and sediment transport formulae to reconcile the computational results with measurements. In this section the fundamental components of 1D models are examined. In particular the effects of simplified continuity equations and the asynchronous solution procedure are addressed, ${ }^{17}$ which have rarely been studied before except for a formative comparison by Krishnappan. $^{18}$

\section{I. Simplified continuity equation for water-sediment mixture}

Alluvial flows over erodible beds can be distinguished from those over fixed beds in that the flow may entrain sediment from the bed or in contrast render the sediment carried by the flow to be deposited on the bed, which usually causes riverbed degradation or aggradation. This aspect is referred to as the bottom mobile (free) boundary problem. At the same time, the water-sediment mixture may have properties (density, etc.) different from clear water. In spite of these apparently known features of erodible-bed alluvial flows, it is often assumed that the rate of bed morphological evolution is of a lower order of magnitude than flow changes with adequately low sediment concentration. Accordingly, in existing 1D and 2D models, the water-sediment mixture continuity equation is almost exclusively assumed to be identical to that for a clear-water flow over a fixed bed without considering the alluvial riverbed mobility. ${ }^{9,10,19-29}$ This simplified mixture continuity equation is, in its form, the same as that in the traditional Saint-Venant equations. The effect of this treatment appears to have been quantitatively addressed only by Correia et al. ${ }^{11}$ and discussed by Rahuel. ${ }^{30}$ Stevens ${ }^{31}$ claimed that bed mobility is important for complete coupling of water and sediment in discussing Lyn's $^{32}$ analysis. Wormleaton and Ghumman ${ }^{23}$ compared the performance of several simplified models, but exclusive of a fully coupled model on a rigorous basis. Therefore the effect of bed mobility on model performance has not been apparent.

\subsection{Simplified continuity equation for global sediment material}

In addition to the widely invoked assumption with respect to the continuity equation for water-sediment mixture, the global bed material continuity equation (hereafter referred to as 'sediment continuity equation') is sometimes simplified by ignoring the temporal change related to sediment discharge or concentration (i.e. sediment storage in the water column. ${ }^{19,21,22,24-29,33-35}$ Similarly in non-equilibrium models in which bed-load and suspended load are separately considered, the temporal variation associated with bed-load discharge is not accounted for. ${ }^{9,10}$ In depth-averaged 2D models, the relevant term is almost exclusively ignored. ${ }^{36}$ In reviewing existing models for river width adjustment, the ASCE Task Committee $^{37}$ state that 'spatial differences in sediment flux ... determine the evolution of the bed topography via solution of the sediment continuity equation'. Actually, the temporal change in relation to sediment discharge is disregarded in the sediment continuity equation. The validity of this simplification in the sediment continuity equation is still far from clear.

\subsection{Simplified equations in analytical models}

It is interesting to note that there have been several analytical models for channel aggradation and degradation. ${ }^{38-47}$ Whereas providing an easy-to-use approach to evaluating the response of channels to the changing of a simple water and sediment hydrograph or base lowering, these models are based heavily on assumptions. First, the flow is assumed to be quasi-steady, leading to the elimination of local derivatives in the watersediment mixture continuity and momentum equations. Second, in the momentum equation the nonlinear convective acceleration term is ignored, yielding a diffusion model for bed elevation evolution. ${ }^{38-40,46,47}$ A slightly modified type of models, namely hyperbolic models have been developed by 
partly including the non-linear convective effect using a perturbation technique. ${ }^{41-45}$

Finally in the sediment continuity equation the temporal concentration term is almost exclusively not taken into account in order to make the analytical solution tractable. One of the major difficulties in using these analytical models is the determination of the model coefficients involved. Additionally, it appears not encouraging to use these analytical models with highly variable hydrographs (complicated boundary conditions). More comments on these analytical models can be found in Zanre and Needham. ${ }^{29}$

It is necessary to recognise that the momentum equation for the mixture flow over erodible bed differs from that of fixed-bed clear water flow (Reference 31, see also closure by Lyn). However, it seems a common practice to reduce it to a clear water flow momentum equation, recognising the uncertainty inherent in the resistance relationship that must be incorporated to close the momentum equation.

\subsection{Equilibrium versus non-equilibrium models}

In equilibrium models sediment transport is assumed to be at its capacity that is prescribed by one of a range of sediment transport functions involving local hydraulic parameters and sediment properties. Often the lumped total-load concept is used without discriminating the physically distinct mechanisms of bed-load and suspended load movements. Obviously the exchange between suspended sediment, bed-load and bed surface material cannot be explicitly represented in equilibrium models. Non-equilibrium models are at least intuitively more advanced than equilibrium models because they account for the limited availability of sediment under some special conditions, and more notably the time and space for sediment transport to adapt to its possible capacity in line with the local flow scenario. Earlier 1D models are mostly equilibrium models and recent ones appear to be non-equilibrium. Since the 1980s, the majority of models developed by Chinese workers are nonequilibrium. ${ }^{2}$ Nevertheless, there has been no study of the methodology whereby non-equilibrium models can be convincingly confirmed to be superior to equilibrium ones because of the uncertainty associated with both types of models.

One of the major sources of uncertainty with equilibrium models comes with the sediment transport function that must be introduced to determine sediment transport rate or discharge. As far as non-equilibrium models are concerned this feature is reflected by the relationships that must be incorporated to determine the net flux of sediment exchange with bed material. Detailed descriptions follow.

\subsection{Sediment transport functions}

To close an equilibrium model, a function is necessary to determine sediment transport rate and, for heterogeneous sediments, the size distribution of bed material being transported. A large number of functions have been developed. However, most, if not all, of these functions have been confirmed using specific laboratory and/or field measurement datasets, and none has been proved to be universally correct. Also it cannot be stated which function is the 'best' to use for a given situation. Distinct sediment transport functions will yield different answers, and normally the sediment rates/discharges are more sensitive to the choice of sediment function than the changes of river morphology. The latter concurs with the known feature that the time-scale of changes in flow variables (velocity, depth and sediment discharge, etc.) is normally significantly less than that of bed evolution. This aspect will be recalled later with respect to the asynchronous solution procedure commonly used in current mathematical river modelling practice. Therefore model developers and end-users have to judge the computational results based on their experience and their understanding of the basis on which existing sediment transport functions were derived and validated. Undoubtedly the modelling output is still subject to model developers and end-users-the lack of objectiveness is apparent.

Using both laboratory and river datasets, Yang and $\mathrm{Wan}^{48}$ compared the performance of several sediment transport functions that are popularly used, and showed that, for river datasets considered, the accuracy in ascending order was Engelund-Hansen, Laursen, Colby, Ackers-White, Einstein, Toffaletti, and Yang. At the same time Yang and $\mathrm{Wan}^{48}$ claimed that the rating does not guarantee that any specific function is better than others under all hydraulic and sediment cases. For gravel-bed rivers, the formulae of Einstein, Parker, and AckersWhite were shown to perform reasonably well. ${ }^{49}$ To measure the applicability of sand transport functions, an 'applicability index' was proposed by Williams and Julien ${ }^{50}$ on the basis of river characteristics. These authors argue that developing a universal (at least to a certain extent) procedure to help choose the 'optimum' sediment transport function among the large pool of candidates will be one of the most realistic strategies to cope with the uncertainty due to sediment transport functions.

\subsection{Model for bed-load transport}

In a number of mathematical river models, bed-load sediment is modelled in a distinct module involving a transport formula (or function) in supplement to the module for suspended sediment. The total sediment transport rate and the global change in bed morphology are computed by summarising the contributions respectively of bed-load and suspended load. It is a commonly accepted belief that the accuracy of existing bed-load formulae is dramatically lower than that of suspended load relationships. Further, this is aggravated by the knowingly spatial and temporal lag of bed-load transport with respect to the change of flow conditions, ${ }^{51-53}$ which renders bed-load transport to be non-equilibrium. This induces much less confidence in mathematical models when bed-load transport dominates. Although a few sporadic formulations have been developed ${ }^{51-54}$ and implemented into $1 \mathrm{D}^{8-10,55,56}$ and even $3 \mathrm{D}^{57}$ models, their validity has only been occasionally shown when applied to specific problems. Furthermore, modelling bed-load sediment transport is made more complicated due to grain sorting of heterogeneous sediments. This is often dealt with based on the concept referred to as 'active layer'. One may refer to Parker et $a l .{ }^{58}$ for a brief description and some new derivations and Pender et $a l .{ }^{59}$ for a flume experimental analysis. An objective assessment of these formulations remains to be made. This status is certainly correct for models of arbitrary spatial dimensions.

\subsection{Net flux of sediment exchange}

A pivotal aspect of non-equilibrium models is the determina- 
tion of the net flux of sediment exchange between the water column and the bed surface. The net flux of sediment exchange with bed material is the difference between the upward entrainment flux due to turbulence and the downward deposition flux under the gravitational action. It is normally defined at a specified reference elevation near the bed. Determining the net flux of sediment exchange is virtually generic to any spatially dimensional models for fluvial sediment transport. In 1D and depth-averaged 2D models, this comes as the closure of the source-sink terms in the mass conservation (or continuity) equation for sediment, whilst it is manifested as specifying the bottom sediment conditions in vertical 2D and 3D models. Given its generic feature, it is reserved as one of the special issues that will be addressed in the companion paper. ${ }^{1}$

\subsection{Resistance relation}

A relationship for hydraulic resistance must be incorporated to close the momentum equation in 1D and 2D models. This involves another important topic in fluvial hydraulics, which has been the theme of a number of studies. Recent analysis can be found in Karim, ${ }^{60} \mathrm{Wu}$ and Wang ${ }^{61}$ and Rooseboom and Grange. $^{62}$

The complexity of fluvial river resistance stems not only from the irregular boundary but the sediments carried by the flow. Since Vanoni's ${ }^{63}$ study, there has been much controversy concerning the effects of sediment on flow resistance (increase or decrease). The earlier works are largely concerned with the idealised steady and longitudinally uniform flow. Vanoni ${ }^{63}$ proposed that flow resistance decreases due to suspended sediment, based on the increase of the mean velocity gradient with sediment concentration along with the reduced von Karman coefficient. ${ }^{64,65}$ On the contrary, Elata and Ippen, ${ }^{66}$ Daily and Roberts ${ }^{67}$ as well as Montes and Ippen ${ }^{68}$ suggested that flow resistance increases because of either neutrally buoyant particles at high concentrations or natural sands of low concentrations. The recent study by Lyn $^{69}$ shows that the flow resistance increases due to dilute suspension of sands.

The effects of suspended sediments on turbulent flow have been studied widely in China. ${ }^{2,3,70}$ The sediments studied are mostly natural fine sand and clay (typically $0 \cdot 1 \mathrm{~mm}$ in medium diameter or finer) at naturally occurring low and high concentrations (up to 0.5 in volume). The results mostly support the contention that flow resistance decreases, resulting from the suppression of turbulence by suspended sediments. The formulation of suspended sediment transport capacity based on this concept has been incorporated in various analytical and mathematical models. ${ }^{2}$

Starting from the law of the wake in the turbulent boundary layer, ${ }^{71}$ Coleman ${ }^{72,73}$ argues that the mean velocity follows the logarithmic profile as in a clear-water flow in the near-bed region, and deviates from that according to the law of the wake near the free surface. The wake intensity varies as a function of sediment concentration. This 'universal' velocity profile is used by Lau, ${ }^{74}$ which inevitably leads to a decreased flow resistance. The novel framework of Lyn, ${ }^{75}$ based on dimensional and matching arguments, requires much empirical input. In its present form, it seems unable to properly represent the effects of suspended sediment on flow resistance.
A more popular approach for suspended sediment-laden flow is based on the wall-bounded slightly stably stratified flow analogy. ${ }^{76-83}$ The gradient Richardson number or, alternatively, the Monin-Obukhov length scale is exclusively invoked, both of which are commonly used for constant flux atmospheric boundary layer. This hierarchy of approaches always results in a reduction of flow resistance. It is necessary to recognise that the validity of this simple analogy is not clear or strictly justified. There exists substantial variability of the model parameters. ${ }^{83}$ McLean ${ }^{84}$ suggests a systematic model for sediment-laden flows using a universal von Karman constant. He finds that the inclusion of stratification effects is necessary but fails to specify accurately the constants that are needed in the parameterisation of the stratification effects. This, as a matter of fact, arises from the lack of existence of physically universal parameters in the stratified flow analogy-based model for sediment-laden flow.

It continues to be difficult to pinpoint the friction factor, especially of natural rivers. Often the Darcy-Weisbach friction factor $(f)$, alternatively the Manning roughness, has to be tuned to reconcile the mathematical modelling outputs with measurements. The uncertainty of this practice does merit clear recognition when assessing model performance. This holds true for 3D models addressed below, except that it is reflected by the boundary hydrodynamic roughness (e.g. $z_{0}$ in the literature) that is invoked in the law of the wall for bottom boundary conditions.

\subsection{Asynchronous solution procedure, quasi-steady flow, and fixed-bed assumptions}

The fluvial water-sediment-morphology system is strongly coupled, as clearly demonstrated in the governing equations of mathematical models. The physical mechanism of the interaction between the various components in the coupled system underlying these formulated equations has been well interpreted in textbooks. ${ }^{85}$ In existing models, these equations are mostly solved in an asynchronous procedure. Specifically, in a given time step, the mixture continuity and momentum equations are solved first, assuming negligible bed change rate (i.e. fixed morphology). Then the sediment continuity equation is solved using the flow variables newly obtained. Models involving the asynchronous solution are usually referred to as decoupled. There have been semi-coupled models in which the flow and bed equations are solved iteratively in a given time step, ${ }^{36,86,87}$ yet the computational cost seems comparable or even higher than the fully coupled models that simultaneously solve the complete set of governing equations. It has been claimed that semi-coupled models permit arbitrary sediment discharge formulae to be easily incorporated. As a matter of fact, fully coupled models also allow for an expedient use of arbitrary sediment discharge formulae, as proposed by Cao and Egashira. ${ }^{17}$

The asynchronous solution procedure is based on the 'fixed bed' and 'quasi-steady flow' assumptions. Often the flow is assumed to be steady when the evolution of the riverbed is studied. Alternatively, the riverbed is implicitly assumed to be 'fixed' within a time step while the flow over the mobile bed is of primary interest. The validity of these assumptions is determined by the typical time-scales or relative magnitudes of the characteristic celerities corresponding to the free-surface 
flow and riverbed evolution respectively. De Vries ${ }^{88,89}$ analysed the relative celerities when the volumetric sediment concentration is negligible. Morris and Williams ${ }^{90}$ confırmed the results of De Vries and extended the analysis to cases with finite sediment concentrations. It has been found that water flow, sediment transport and riverbed evolution can be considered to be mathematically independent of each other only within very limited ranges of total-load concentration and Froude number. Beyond these ranges, the 'quasi-steady state' or 'fixed bed' assumption is no longer reasonable. Cao and Egashira ${ }^{91}$ further extended the analysis of Morris and Williams. ${ }^{90}$ They found that when sediment is transported predominantly in suspension or within limited ranges of bedload (rather than total load) concentration and Froude number, the flow, sediment and riverbed can be solved asynchronously and thus the 'quasisteady state' and 'fixed bed' assumptions are justified. Based on the Saint-Venant equations, $\mathrm{Lyn}^{32}$ identified the multiple timescales of the flow-sediment-riverbed system. He showed that previous models, which reduce the number of conservation equations to be solved simultaneously from three to two under the 'quasi-steady state' or 'fixed bed' assumption, are unable to satisfy exactly either a general boundary condition or an arbitrary initial condition. And in situations with highly variable discharge and sediment inputs, the afore-mentioned assumption is not justified. Needham and his colleagues ${ }^{25,27-29}$ carried out a thorough analysis of the hyperbolic system for alluvial river flows based on simplified equations. Despite the studies stated above, the quantitative effect of the asynchronous solution procedure is not as yet fully understood.

Physically, riverbed deformation results from unbalanced sediment exchange between the water column and the bed surface. Two distinct processes are involved in sediment exchange-that is, bed sediment entrainment due to turbulence and sediment deposition due to gravitation. ${ }^{6}$ The rate of the sediment exchange can be scaled to $\boldsymbol{w C}$ (where $\boldsymbol{w}$ is the representative sediment settling velocity, and $C$ is the mean volumetric sediment concentration). Thus the time-scale of bed deformation is $T_{\mathrm{B}}=h / \boldsymbol{w} C$ (where $h$ is the flow depth). As the time-scale of the flow is $T_{\mathrm{F}}=h / \boldsymbol{U}$ (where $\boldsymbol{U}$ is the mean velocity), then one can define the relative time-scale of bed deformation as

\begin{tabular}{|l|l|}
\hline $\mathrm{I}$ & $R_{\mathrm{T}}=\frac{T_{\mathrm{B}}}{T_{\mathrm{F}}}=\frac{\boldsymbol{U}}{\boldsymbol{w C}}$ \\
\hline
\end{tabular}

By equation (1) it is indicated that the time-scale of bed deformation is generally larger than that of the flow because of low sediment concentration and settling velocity compared to the flow velocity. This is the basis on which decoupled modelling has been commonly used over the decades. However, there has been no quantitative measure of $R_{\mathrm{T}}$ for decoupling to be acceptable. It is interesting to consider the sediment-laden flood-induced bed evolution processes in the middle and lower Yellow River, China. Assume a typical volumetric sediment concentration of $0 \cdot 1\left(265 \mathrm{~kg} / \mathrm{m}^{3}\right)$, a representative sediment particle diameter of $0.06 \mathrm{~mm}$ (with $\boldsymbol{w}=0.226 \mathrm{~cm} / \mathrm{s}$ ), and flow velocity $1.0 \mathrm{~m} / \mathrm{s}$, then the relative time-scale of bed deformation is equal to $4424 \cdot 8$. A variety of decoupled river models have proven to fail when applied to the Yellow River flooding processes. This implies that in such cases with $R_{\mathrm{T}}$ of an order of magnitude of 4000, the synchronous solution should be pursued if the rapid bed evolution process is to be modelled correctly.

\subsection{Numerical schemes for strong hyperbolic equations}

The governing equations of 1D models for the fluvial flowsediment-morphology system are generally hyperbolic. ${ }^{28}$ Perhaps in most cases the river flows are subcritical and therefore the daily used numerical schemes are effective and efficient. However there do exist some natural flow situations for which specially developed numerical schemes must be devised to cope with the strong hyperbolic nature, for example, extreme floodinduced degradation and dam-break flow over erodible bed. In fact the mobile-bed dam-break flow problem has been insufficiently studied, albeit there has been an EU Concerted Action on Dam Break Modelling program ${ }^{92}$ and also a great number of investigations of 1D and 2D numerical models for dam-break flows over fixed boundaries. ${ }^{93,94}$ There is scope for basic studies of advanced numerical schemes for the strong hyperbolic equations, which can be used for the mixed suband supercritical river flows, intense sediment transport and rapid morphological evolution. In this regard the complete continuity equations must be synchronously solved. The significance of this observation is shown in the test example that follows, as related to the aggradation process induced by sediment overloading.

It is well-known that for mobile-bed river models, the first flow-related and bed-related celerities are positive, and the second flow-related celerity is invariably negative, irrespective of the Froude number (either super- or subcritical flow) and sediment concentration. The latter is in sharp contrast to the fixed-bed cases, in which the second flow-related celerity is dependent on Froude number. Accordingly, for mobile-bed problems the influences from both upstream and downstream need to be properly considered. One the other hand, the numerical difficulties with the so-called 'mixed-flow' or 'transcritical flow' under fixed-bed situations may no longer exist, or at least be alleviated in mobile-bed cases. Seemingly decoupling the flow equations from the sediment continuity equation simplifies the solution procedure. However it is the artificial decoupling that gives rise to the need for extra and often cumbersome treatment to facilitate the boundary conditions and to ensure stability, including the special discretisation schemes to be adopted. ${ }^{35,95}$

\section{II. Coupled and decoupled models: a test example}

A numerical example of river aggradation due to sediment overloading is given below. ${ }^{17,96}$ The behaviour of $(a)$ simplified continuity equations for the water-sediment mixture and global bed material; and $(b)$ the asynchronous solution procedure is addressed, in comparison with the role of tuned friction factor. Equilibrium models are used as an illustration, and the sediment transport function is derived from experiments. ${ }^{38}$ According to the governing equations and the numerical solution procedures used, the various types of models are summarised in Table 2. FCM denotes a fully coupled model that employs the complete equations and synchronous solution procedure. PCM means partially coupled model as the equations are simplified compared to FCM (but are solved simultaneously). DCM indicates decoupled model characterised by the asynchronous solution procedure utilised. 


\begin{tabular}{|c|c|c|}
\hline Model & Governing equations & $\begin{array}{c}\text { Numerical solution } \\
\text { procedure }\end{array}$ \\
\hline FCM & Complete & Synchronous \\
\hline PCMI & Bed mobility neglected & Synchronous \\
\hline PCM2 & $\begin{array}{l}\text { Sediment storage in water } \\
\text { column neglected }\end{array}$ & Synchronous \\
\hline DCM & Bed mobility neglected & Asynchronous \\
\hline
\end{tabular}

The test case is concerned with the aggradation process due to sediment overloading. The flume dataset of Soni et al. ${ }^{38}$ is referred to for quantitative comparison of the models. The initial condition was an equilibrium state under constant discharge and sediment load. Sediment overloading was activated by feeding additional sediment at the upstream end while water discharge remained unaltered. The case with the ratio of increased sediment discharge to initial equilibrium value being 4.0 is considered here. An earlier numerical modelling of the aggradation process can be found in Bhallamudi and Chaudhry. ${ }^{97}$

To quantitatively measure the performance of a numerical model solution as compared to a reference FCM solution based on complete governing equations and synchronous solution procedure, the normalised change of bed elevation is defined as

\begin{tabular}{|c|c|}
\hline 2 & $Y_{\text {nor }}=\frac{\Delta Y(x, t)}{\Delta Y(x, t)_{\mathrm{REF}}}$ \\
\hline
\end{tabular}

For measurement of the overall difference between two model solutions, the normalised $L_{1}$ norm between changes of bed elevation is defined as

\begin{tabular}{|c|c|}
\hline 3 & $L_{1}=\frac{\sum_{i=1}^{N} a b s\left[\Delta Y(x, t)-\Delta Y(x, t)_{\mathrm{REF}}\right]}{\sum_{i=1}^{N} a b s\left[\Delta Y(x, t)_{\mathrm{REF}}\right]}$ \\
\hline
\end{tabular}

where $x$ is the streamwise coordinate, $t$ is the time, $\Delta Y(x, t)$ is the change of bed elevation, the subscript 'REF' denotes the reference FCM solution, and $N$ the total computational node number. A perfect agreement between two solutions corresponds to $Y_{\text {nor }} \equiv 1$, and $L_{1} \equiv 0$.

Figure 1 shows the normalised change of bed elevations of partially coupled models (PCM1 and PCM2). In running all the models, FCM, PCM1 and PCM2, the same value of friction factor is used $\left(R f=f / f_{0}=0 \cdot 8\right.$, defined as the ratio of friction factor used to that under the initial equilibrium state). Within the time period shown, riverbed aggradation is significantly underestimated by PCM1 and PCM2 as the value of the normalised change of bed elevation is less than unity (Fig. 1), and the underprediction by PCM1 or PCM2 becomes steadily more pronounced with increasing computational time due to error accumulation. For other experimental cases with less

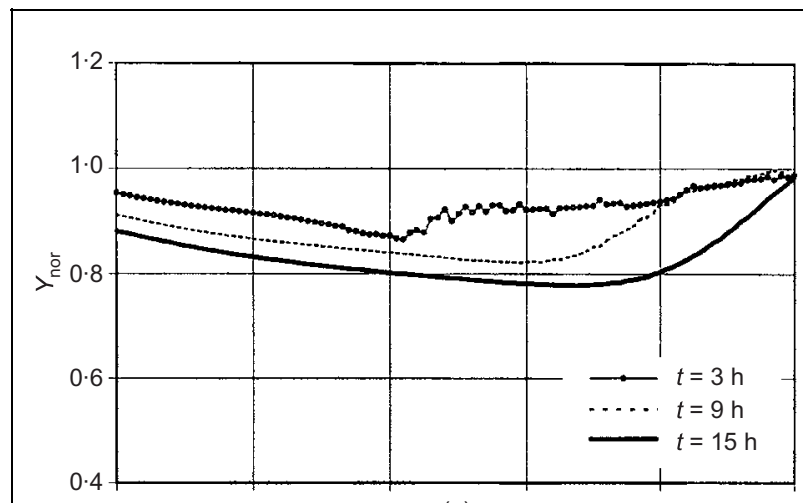

(a)

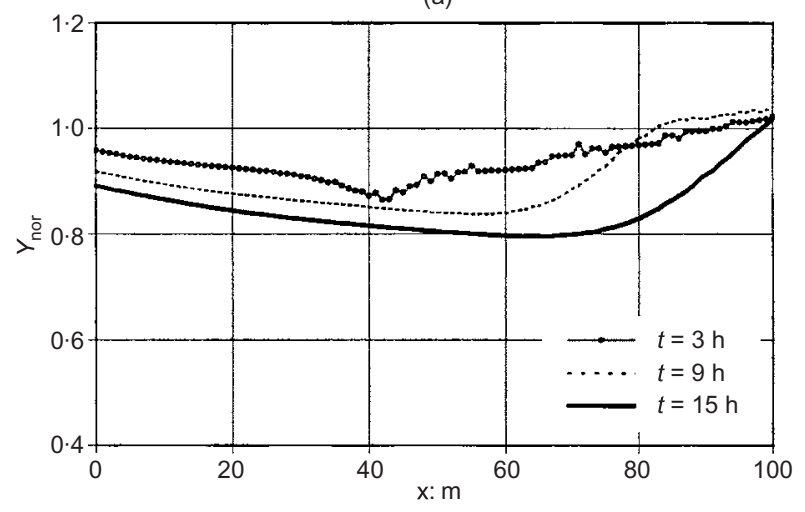

(b)

Fig. I. Normalised change of bed elevations of: (a) PCMI; and (b) PCM2

overloading, the difference between FCM and PCM1 or PCM2 is less significant but still appreciable.

As interpreted in Cao and Egashira, ${ }^{17}$ a decoupled solution for this case is hampered by unavailability of an additional upstream boundary condition when $\mathrm{Fr}>1$ immediately after overloading is started. In other words, decoupled modelling is rendered mathematically ill-posed and unachievable, which is caused solely by the asynchronous solution procedure.

It is known that considerable uncertainty may arise due to the resistance relationship that must be implemented to close the momentum equation. Often the friction factor (alternatively Manning's coefficient) in a resistance relation is tuned to reconcile modelling output with measurements. Apparently, it is interesting to see if the impacts of the partially coupled and decoupled models (Table 2) are comparable with those of solely tuned friction factors. Fig. 2 shows the normalised $L_{1}$ norm between the changes of bed elevation for the present case. The influences of the partially coupled models increase steadily with time, being comparable with (greater than) those of tuned friction factors (FCM: $R f=0.72$ and 0.89 ) within (after) roughly $7 \cdot 5 \mathrm{~h}$ of overloading. The significance of the use of complete continuity equations is thus evident for the calibration of models.

Natural alluvial rivers are subject to significant changes of water and sediment discharges with movable bed boundary. The rate of bed evolution can be high under some conditions. For instance, in the middle and lower Yellow River, China, it can be up to several metres within a few days in flooding 


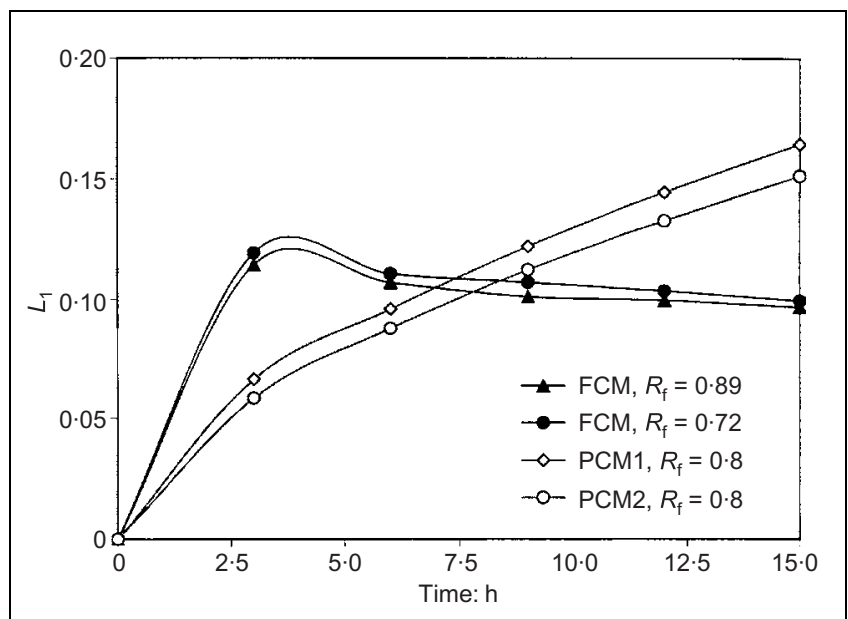

Fig. 2. Normalised $L_{1}$ norm between changes of bed elevation

seasons. ${ }^{2,3}$ In numerical models for such river processes, simplifying the mixture continuity equation (as for that over a fixed bed) and sediment continuity equation (neglecting sediment storage in the water column) can lead to substantial inaccuracy. This inaccuracy can be cumulative and become more pronounced progressively with increasing computational time. The asynchronous solution procedure either renders the physical process mathematically ill-posed in supercritical regimes or results in considerable errors. Further, these impacts are comparable with those of largely tuned friction factors, characterising their significance in calibrating numerical river models. Consequently, it is necessary to use the complete mixture and sediment continuity equations and also synchronous solution procedure for refined modelling of alluvial rivers. The use of asynchronous solution of simplified continuity equations is likely the major reason that a number of models have proved to fail for the routing of sediment-laden floods in the Yellow River.

\section{3D MATHEMATICAL RIVER MODELS}

With the advancement of computer technology, 3D modelling has been becoming more and more attractive because of the very detailed information that can be acquired from these models in contrast to the comparatively simpler $1 \mathrm{D}$ and $2 \mathrm{D}$ hydraulics models. There is significant merit in the move towards 3D models, although substantial research is required to incorporate methods developed in other fields for dealing with boundary condition uncertainties. ${ }^{98}$ In an attempt to model the flow over and morphological evolution of dunes, Carling et al. ${ }^{99}$ found that a (vertical) 2D model is unable to reproduce the flow and dune evolution process. This stems from the incapability of the vertical 2D model to reflect the spanwise (or transverse) variation of the flow structure, the unavailability of appropriate formulations for bed-load movement, and the sophisticated turbulence-sediment interaction over the dune. ${ }^{99}$ More broadly, for strongly localised flow-sediment-morphology problems (e.g. local scour around structures), mathematical modelling is still in its infancy, ${ }^{100}$ far from being of mature use in engineering practice.

\section{I. RANS against DNS and LES}

Currently direct numerical simulation (DNS) and large eddy simulation (LES) are only applicable to idealised flows with regular and fixed geometry and will not be of significant benefit to end-users in the foreseeable future. Full 3D modelling of turbulent flows are mostly built upon the ReynoldsAveraged Navier-Stokes (RANS) equations with the aid of a turbulence closure module. The complete Reynolds stress closure module involves a large number of partial differential equations to be solved and its superiority over eddy viscositybased models (say, two-equation models) for mean flow quantities is, if ever, merely marginal or limited in most cases. ${ }^{101,102}$ It is also demanding in computing cost for any large-scale realistic river problems. Therefore turbulent eddy viscosity-based closure modules continue to be most widely utilised and have seen considerable success in engineering practice. The turbulent closure is one of the key issues within the framework of full 3D river modelling and will be detailed in the companion paper. ${ }^{1}$

\subsection{Two-fluid, particle-tracking, and algebraic slip mixture models for suspended sediment}

In light of the distinct treatment of suspended sediment particles in line with fluid flow, models for suspended sediment can be categorised into

(a) two-fluid models

(b) particle-tracking models

(c) algebraic slip mixture (ASM) models.

In two-fluid models, both the fluid phase (water) and the dispersed sediment particle phase are respectively considered as a continuum, with each phase having its own continuity and momentum equations. The governing equations for both phases are described by Drew, ${ }^{103}$ which are coupled through an interphase momentum exchange term. The interactions due to sediment particle-particle collisions, which are important for high concentration cases, are accounted for by semi-empirical constitutive relationships incorporated into the solid-phase momentum balance equation. Satisfactory performance of two models of this kind has been reported by Villaret and Davies ${ }^{104}$ for relatively high concentration flows. Nevertheless, it must be noted that

(a) the continuum assumption for dispersed sediment phase is questionable, especially for low sediment concentration flows as is in most natural rivers

(b) the knowledge of distinct turbulence behaviour of water and sediment phases is fragmentary, which causes much more uncertainty in the closure methods of the turbulent correlations

(c) the computing cost is high due to the momentum equations for sediment phase to be solved.

As far as the particle tracking models are concerned, sediment particles are tracked using the kinematic equation involving the fluid velocity field. A statistical analysis is warranted to acquire the time-dependent distribution of particles in terms of sediment concentration, discharge, etc. There have been some reports of this kind of models for idealised situations with regular flow boundaries, etc. The following concerns over the suitability of these models for suspended sediment in natural rivers should be recognised. 
(a) the impractical computational cost, especially for fine sediment transport in large-scale natural rivers due to the prohibitively huge number of sediment particles to be tracked

(b) the difficulty in implementing the particle-bed interaction due to irregular natural river boundaries

(c) the particle-particle interactions that may need to be accounted for, particularly in the near-bed region.

The algebraic slip mixture models are probably the most widely used, in which the water-sediment mixture is considered as a continuum in the continuity and momentum equations. The sediment phase is calculated based on a separate continuity equation, within which the sediment velocity is computed from the mixture's velocity plus an algebraic relative slip velocitythat is, sediment settling velocity due to gravitational action. The following context, where applicable, is devoted to issues associated with the ASM models.

\subsection{The bottom boundary conditions}

Within the framework of RANS for the water-sediment mixture flow, a turbulent closure model and the ASM for suspended sediment, one of the major issues is with specifying the bottom boundary conditions. In light of the physics of sediment transport in alluvial rivers, this is actually the core of the phenomenon. In the near-bed zone, turbulence production and dissipation occurs, and there is strong interaction between turbulence and sediment. In the context of mathematical modelling, this is manifested in the bottom boundary conditions for mean quantities. For instance with the $\kappa-\epsilon$ turbulence closure model, bottom boundary conditions must be specified for the mean velocity components, turbulent kinetic energy and dissipation rate as well as the mean flux of sediment exchange, etc. Although the present overview is not intended to fully review the dynamics of sediment transport, it is necessary to recognise the basis on which the bottom boundary conditions are formulated, so that the corresponding uncertainty can be fairly appreciated. Due to its pivotal role in mathematical river modelling, this is reserved as one of the special issues to be covered in the companion paper. ${ }^{1}$

\subsection{Free surface and movable bottom boundary implementation}

The free surface dynamic boundary condition provides that the normal stress and shear stresses are equal to zero (neglecting the vanishingly small viscosity of air and surface tension), while the free surface kinematic boundary condition states that a material point on the boundary remains on the boundary. The complete boundary conditions have been widely utilised in the field of computational fluid dynamics, including large eddy simulations. ${ }^{105}$ However, in the field of river hydraulics, the complete free surface conditions have not been rigorously incorporated. Conventionally, the free surface has been implemented using, for simplicity, hydrostatic pressure distribution with rigid-lid assumption, or based on the shallow water premise, ${ }^{57}$ which virtually renders the $3 \mathrm{D}$ flow field not fully uncovered. In this connection there is an evident ambiguity that remains to be assessed. Dating back to Hirt and Nichols, ${ }^{106}$ the strict VOF (volume of fluid) method has been widely implemented in flow codes. An alternative method to the free surface seems to be the (non-adaptive or adaptive) $\sigma$-transformation, with which the rigorous kinematic and dynamic conditions are preserved. ${ }^{107}$ The proper implementation of the free surface can be indispensable when turbulent mixing near the free surface is to be modelled and that may influence fine suspended sediment transport.

As the interface between flow and riverbed, the bottom boundary of the flow may be movable because of the generally unbalanced entrainment and deposition fluxes of sediment. Its elevation is determined by the mass conservation (continuity) of sediment material. In the case of $1 \mathrm{D}$ and 2D modelling, this is represented by a term in the mass conservation equation for the water-sediment mixture. Its significance has been reviewed and shown in the previous section (Figs 1 and 2). In 3D modelling a formulation of this continuity can be easily derived, which is in its form similar to the kinematic condition for the free surface. ${ }^{85}$ Nevertheless, the movable bottom boundary is unique in that the exchange of sediment across the bottom boundary continues to be one of the major challenges in fluvial sediment transport (as stated below). Moreover, the dynamic condition at the movable bottom boundary has been implemented, without exception, based on the law of the wall with respect to a fixed boundary. The validity of this treatment is far from clear, which is in contrast to that at the free surface where the shear and normal stresses are negligible in river flows.

\subsection{Complex natural river plane geometry and bank migration}

Generally, the plane river geometry is meshed using boundaryfitted coordinates. However, when riverbank erosion occurs as in many rivers (say, meandering rivers with erodible banks), the river width adjusts, which renders the plane geometry movable (time-dependent). A review of the mechanism and modelling of river width adjustment can be found in ASCE. ${ }^{37}$ If one continues to employ boundary-fitted coordinates based on the solution of partial differential equations (e.g. elliptic operator problems such as Poisson equations), the timely tracking of the movable plane geometry (river banks) undoubtedly entails much higher computing cost. The need is evident for more efficient representation of the irregular and movable plane geometry (perhaps an algebraic transformation-based representation would be a good choice). The modelling of riverbank erosion can be extremely intriguing. Recent work in the framework of 1D and 2D hydraulics modelling can be found in Darby, ${ }^{108}$ Darby and Thorne, ${ }^{109-111}$ Darby et al., ${ }^{112}$ and ASCE, ${ }^{37}$ which represent the current state of the art.

\section{CONCLUSIONS}

Mathematical models for alluvial rivers (flow-sediment-morphology systems) are at best imperfectly constructed, and at worst invalid. A number of crucial issues have been reviewed, for which solutions are still far in the future. Primarily these include the sediment transport and entrainment functions, resistance relationship (or hydrodynamic roughness) and turbulence closure model that must be implemented to close the governing equations and to specify the bottom boundary conditions. These issues become more acute when heterogeneous and bed-load sediment transport dominate. The numerical solution procedure (synchronous versus asynchronous) and discretisation schemes are the other major factors that bring extra uncertainty to mathematical river models, especially for strong hyperbolic problems. 
The significance of these issues may vary from river to river, but for all existing mathematical river models the awareness of these issues is generally meagre. These issues represent some of the most basic problems in fluid mechanics, sediment transport dynamics, and numerical mathematics. The authors do not wish the list in Table 1 to be construed as an appeal to include all variables related to these issues, which would otherwise make the models more complex. What should be incorporated in specific models must be examined in isolation. Normally more adjustable parameters render river models more flexible in reconciling modelling outputs to observations, but at the same time introduce additional uncertainty and thus less confidence.

The issues of sediment entrainment functions and turbulence closure models characterise the currently incomplete knowledge of the physics of fluvial sediment transport and constitute the core of the discipline in question. Also because of the uncertainties in mathematical river models, proper assessment of model performance (calibration, verification or validation) is significant. Given their crucial role in dictating the quality of mathematical river modelling, detailed discussions of these issues follow in the companion paper. ${ }^{1}$

\section{ACKNOWLEDGEMENTS}

Financial support from the National Natural Science Foundation of China, under Grant 59890200-3, is gratefully acknowledged. The authors are indebted to the anonymous reviewers for their constructive comments on an earlier version of the manuscript. Special thanks also go to several colleagues who carefully reviewed the revised manuscripts through private communications.

\section{REFERENCES}

1. Cao Z. and Carling P. A. Mathematical modelling of alluvial rivers: reality and myth. Part II: special issues. Proceedings of the Institution of Civil Engineers, Water and Maritime Engineering, 2002, 154 (in press).

2. ZhANG R. and XIE J. Sedimentation Research in China: Systematic Selections. China Water and Power Press, Beijing, 1993 (in English).

3. Chien N. and WAN Z. Mechanics of Sediment Transport. ASCE Press, VA, 1999.

4. Zyserman J. A. and FredsøE J. Data analysis of bed concentration of suspended sediment. Journal of Hydraulic Engineering, ASCE, 1994, 120, No. 9, 1021-1042.

5. CAO Z. Turbulent bursting-based sediment entrainment function. Journal of Hydraulic Engineering, ASCE, 1997, 123, No. 3, 233-236.

6. CAO Z. Equilibrium near-bed concentration of suspended sediment. Journal of Hydraulic Engineering, ASCE, 1999, 125, No. 12, 1270-1278.

7. XIE J. and WEI L. Review and prospectus of mathematical modelling of river sediment. Journal of Sediment Research, 1987, 1, 1-12 (in Chinese).

8. Rahuel J. L., Holly F. M. Jr., Chollet J. P., Belleudy P. J. and YANG G. Modelling of riverbed evolution for bedload sediment mixtures.' Journal of Hydraulic Engineering, ASCE, 1989, 115, No. 11, 1521-1542.

9. Holly F. M., Jr. and RAhUEl J. L. New numerical/physical framework for mobile-bed modelling, part 1: numerical and physical principles. Journal of Hydraulics Research, IAHR, 1990, 28, No. 4, 401-416.
10. Holly F. M., Jr. and Rahuel J. L. New numerical/physical framework for mobile-bed modelling, part 2: test applications. Journal of Hydraulics Research, IAHR, 1990, 28, No. $5,545-564$.

11. Correia L. R. P., Krishnappan B. G. and Graf W. H. Fully coupled unsteady mobile boundary flow model. Journal of Hydraulic Engineering, ASCE, 1992, 118, No. 3, 476-494.

12. Vanniekerk A., Vogel K. R., Slingerland R. L. and Bridge J. S. Routing of heterogeneous sediments over movable bed-model development. Journal of Hydraulic Engineering, ASCE, 1992, 118, No. 2, 246-262.

13. Vogel K. R., VAnNiekerk A., Suingerland R. L. and Bridge J. S. Routing of heterogeneous sediments over movable bed-model verification. Journal of Hydraulic Engineering, ASCE, 1992, 118, No. 2, 263-279.

14. Ghumman A. R., Wormleaton P. R., Hashimi H. N. and AKBARI G. H. Parameter identification for sediment routing on rivers. Journal of Hydraulic Research, IAHR, 1996, 34, No. 4, 473-480.

15. CuI Y., Parker G. and Padla C. Numerical simulation of aggradation and downstream fining. Journal of Hydraulic Research, IAHR, 1996, 34, No. 2, 195-204.

16. Guo Q. and Jin, Y. Modelling sediment transport using depth-averaged and moment equations. Journal of Hydraulic Engineering, ASCE, 1999, 125, No. 12, 12621269.

17. CAO Z. and Egashira S. Coupled mathematical modelling of alluvial rivers. Journal of Hydroscience and Hydraulic Engineering, JSCE, 1999, 17, No. 2, 71-85.

18. Krishnappan B. G. Comparison of MOBED and HEC-6 river flow models. Canadian Journal of Civil Engineering, 1985, 12, 464-471.

19. Cunge J. A., Holly F. M. Jr. and Verwey A. Practical Aspects of Computational River Hydraulics. Pitman, London, 1980.

20. JaRAmillo W. F. and Jain S. C. Aggradation and degradation of alluvial-channel beds.' Journal of Hydraulic Engineering, ASCE, 1984, 110, No. 8, 1072-1085.

21. Lu J. and SHEN H. W. Analysis and comparisons of degradation models. Journal of Hydraulic Engineering, ASCE, 1986, 112, No. 4, 281-299.

22. Chang H. H. Fluvial Processes in River Engineering. Wiley Interscience, New York, 1988.

23. Wormleaton, P. R. and Ghumman, A. R. A comparison of the performance of coupled/decoupled and linear/nonlinear solutions of the $1 \mathrm{D}$ sediment routing equations. Proceedings of the 5th Conference on Hydraulic Engineering and Software (BLAIN W. R. et al. (eds)). Computer Mechanics Publishing, Southampton, 1994, Vol. 2, pp. 99-106.

24. SIEBEN J. A theoretical analysis of discontinuous flow with mobile bed. Journal of Hydraulic Research, IAHR, 1999, 37, No. 2, 199-212.

25. NeEdHAm D. J. Wave hierarchies in alluvial river flows. Geophysical and Astrophysical Fluid Dynamics, 1990, 51, 167-194.

26. Morse B., Townsend R. D. and Sydor M. Mathematical modelling of riverbed dynamics-a Canadian case study. Canadian Journal of Civil Engineering, 1991, 18, 772-780.

27. NeEdHAm D. J. and Hey R. D. On nonlinear simple waves in alluvial river flows: a theory for sediment bores. Philosophical Transactions of the Royal Society of London, A, 1991, 334, 25-53. 
28. ZanRe D. D. L. and NeEdham D. J. On the hyperbolic nature of the equations of alluvial river hydraulics and the equivalence of stable and energy dissipating shocks. Geophysical and Astrophysical Fluid Dynamics, 1994, 76, 193-222.

29. ZANRE D. D. L. and NeEDHAM D. J. On simple waves and weak shock theory for the equations of alluvial river hydraulics. Philosophical Transactions of the Royal Society London, A, 1996, 354, 2993-3054.

30. RAHUEL J. L. Discussion on: fully coupled unsteady mobile boundary flow model. Journal of Hydraulic Engineering, ASCE, 1993, 119, No. 4, 528-530.

31. Stevens M. A. Discussion on: Unsteady sediment transport modelling. Journal of Hydraulic Engineering, ASCE, 1988, 114, No. 8, 954-956.

32. LYN D. A. Unsteady sediment transport modelling. Journal of Hydraulic Engineering, ASCE, 1987, 113, No. 1,1-15.

33. Ponce V. M., Garcia J. L. and Simons D. B. Modelling alluvial channel transients. Journal of the Hydraulics Division, ASCE, 1979, 105, No. 3, 245-256.

34. Holly F. M., Jr. and Karim M. F. Simulation of Missouri River bed degradation. Journal of Hydraulic Engineering, ASCE, 1986, 112, No. 6, 497-517.

35. Busnelli M., Stelling G. and Larcher M. Numerical morphological modelling of open-check dams. Journal of Hydraulic Engineering, ASCE, 2001, 127, No. 2, 105-114.

36. KASSEM A. and Chaudhry M. H. Comparison of coupled and semicoupled numerical models for alluvial channels. Journal of Hydraulic Engineering, ASCE, 1998, 124, No. 8, 794-802.

37. ASCE TASK Committee. River width adjustment. Journal of Hydraulic Engineering, ASCE, 1998, 124, No. 8, 881917.

38. Soni J. P., GARde R. J. and RAJU K. G. Aggradation in streams due to overloading. Journal of the Hydraulics Division, ASCE, 1980, 106, No. 1, 117-132.

39. GILL M. A. Diffusion model for aggrading channels. Journal of Hydraulic Research, IAHR, 1983, 21, No. 5, 355-367.

40. GILL M. A. Diffusion model for degrading channels. Journal of Hydraulic Research., IAHR, 1983, 21, No. 5, 369-378.

41. GILL M. A. Nonlinear solution for aggradation and degradation in channels. Journal of Hydraulic Research, IAHR, 1987, 25, No. 5, 537-547.

42. ZHANG H. and KAHAWITA R. Nonlinear model for aggradation in alluvial channels. Journal of Hydraulic Engineering, ASCE, 1987, 113, No. 3, 353-369.

43. Zhang H. and Kahawita R. Nonlinear hyperbolic system and its solution for aggraded channels. Journal of Hydraulic Research, IAHR, 1988, 26, No. 3, 323-342.

44. ZHANG H. and KAHAWITA R. Linear hyperbolic model for alluvial channels. Journal of Hydraulic Engineering, ASCE, 1990, 116, No. 4, 478-493.

45. Ribberink J. S. and VAn der SAnde J. T. M. Aggradation in rivers due to overloading-analytical approaches. Journal of Hydraulic Research, IAHR, 1985, 23, No. 3, 273-283.

46. BEgin Z. B. Application of a diffusion-erosion model to alluvial channels which degrade due to base-level lowering. Earth Surface Processes and Landforms, 1988, 13, No. 6, 487-500.

47. Lenau C. W. and HJelmfelt A. T. River bed degradation due to abrupt outfall lowering. Journal of Hydraulic Engineering, ASCE, 1992, 118, No. 6, 918-933.
48. YANG C. T. and WAN S. Comparisons of selected bedmaterial load formulas. Journal of Hydraulic Engineering, ASCE, 1991, 117, No. 8, 973-989.

49. Gomez B. and Church M. An assessment of bed load sediment transport formulae for gravel bed rivers. Water Resource Research, 1989, 25, No. 6, 1161-1186.

50. Williams D. T. and Julien P. Y. Applicability index for sand transport equations. Journal of Hydraulic Engineering, ASCE, 1989, 115, No. 11, 1578-1581.

51. Bell R. G. and Sutherland A. J. Non-equilibrium bedload transport by steady flow. Journal of Hydraulic Engineering., ASCE, 1983, 109, No. 3, 351-367.

52. Phillips B. and Sutherland A. J. Spatial lag effects in bedload sediment transport. Journal of Hydraulic Research, IAHR, 1989, 27, No. 1, 115-133.

53. Phillips B. and Sutherland A. J. Temporal lag effects in bed-load sediment transport. Journal of Hydraulic Research, IAHR, 1990, 28, No. 1, 5-23.

54. JAIN S. C. Note on lag in bedload discharge. Journal of Hydraulic Engineering, ASCE, 1992, 118, No. 6, 904-917.

55. Pender G. and LI Q. Comparison of two hiding function formulations for non-uniform sediment transport calculations. Proceedings of the Institution of Civil Engineers, Water, Maritime and Energy, 1995, 112, No. 2, 127-135.

56. Pender G. and Li Q. Numerical prediction of graded sediment transport. Proceedings of the Institution of Civil Engineers, Water, Maritime and Energy, 1996, 118, No. 4, 237-245.

57. Wu W., Rodi W. and WeNKA T. 3D numerical modelling of flow and sediment transport in open channels. Journal of Hydraulic Engineering, ASCE, 2000, 126, No. 1, 4-15.

58. Parker G., Paola C. and Leclaire S. Probabilistic Exner sediment continuity equation for mixtures with no active layer. Journal of Hydraulic Engineering, ASCE, 2000, 126, No. 11, 818-826.

59. Pender G., Hoey T., Fuller C. and McEwan I. Selective bedload transport during the degradation of a well sorted graded sediment. Journal of Hydraulic Research, IAHR, 2001, 39, No. 3, 269-277.

60. KARIM F. Bed configuration and hydraulic resistance in alluvial channel flows. Journal of Hydraulic Engineering, ASCE, 1995, 121, No. 1, 15-25.

61. WU W. and WANG S. S. Y. Movable roughness in alluvial rivers. Journal of Hydraulic Engineering, ASCE, 1999, 125, No. 12, 1309-1312.

62. Rooseboom A. and Grange A. L. The hydraulic resistance of sand streambeds under steady flow conditions. Journal of Hydraulic Research, IAHR, 2000, 38, No. 1, 27-35.

63. VANONI V. A. Transportation of suspended sediment by water. Transactions ASCE, 1946, 111, 67-133.

64. Einstein H. A. and ChiEN N. Effects of heavy sediment concentration near the bed on the velocity and sediment distribution. M.R.D. Sediment Series No. 8, Institute of Engineering Research, University of California, Berkeley, 1955.

65. VAnONI V. A. and Nomicos G. N. Resistance properties of sediment-laden streams. Transactions ASCE, 1960, 125, 1140-1175.

66. Elata C. and Ippen A. T. Dynamics of Open Channel Flow with Suspensions of Neutrally Buoyant Particles MIT, Hydrodynamics Laboratory, Cambridge, Massachusetts , 1961, Technical Report No. 45. 
67. Daily J. W. and Roberts C. P. R. Rigid Particle Suspensions in Turbulent Shear Flows: Size Effects with Spherical Particles. MIT, Hydrodyn. Lab., Massachusetts, 1964, Technical Report No. 69.

68. Montes J. S. and IPPEN A. T. Interaction of $2 D$ Turbulent Flow with Suspended Particles. MIT, Cambridge, Massachusetts, 1973, Report 164.

69. LYN D. A. Resistance in flat-bed sediment-laden flows. Journal of Hydraulic Engineering, ASCE, 1991, 117, No. 1, 94-114.

70. WAN Z. and WANG Z. Hyperconcentrated Flow. IAHR Monograph, Balkema, Rotterdam, 1994.

71. CoLES D. The law of the wake in the turbulent boundary layer. Journal of Fluid Mechanics, 1956, 1, 191-226.

72. Coleman N. L. Velocity profiles with suspended sediment. Journal of Hydraulic Research, IAHR, 1981, 19, No. 3, 211-229.

73. Coleman N. L. Effects of suspended sediment on the openchannel velocity distribution. Water Resource Research, 1986, 22, No. 10, 1377-1384.

74. LAU Y. L. Suspended sediment effect on flow resistance. Journal of Hydraulic Engineering, ASCE, 1983, 109, No. 5, 757-763.

75. LYN D. A. A similarity approach to turbulent sedimentladen flows in open channels. Journal of Fluid Mechanics, 1988, 193, 1-26.

76. BARENBLATT G. I. Motion of suspended particles in a turbulent flow. Prikl. Mat. Mekh, 1953, 17, 261-274 (in Russian).

77. Barenblatt G. I. Motion of suspended particles in a turbulent flow occupying a half-space or plane channel of finite depth. Prikl. Mat. Mekh, 1955, 19, 61-68 (in Russian).

78. Smith J. D. and Mclean, S. R. Spatially averaged flow over a wavy surface. Journal of Geophysical Research., 1977, 82, No. 12, 1735-1746.

79. ITAKURA T. and KISHI T. Open channel flow with suspended sediments. Journal of the Hydraulics Division, ASCE, 1981, 106, No. 8, 1325-1343.

80. Soulsby R. L. and Wainwright B. L. S. A. Criterion for effect of suspended sediment on near-bottom velocity profile. Journal of Hydraulic Research, IAHR, 1987, 25, No. 3, 341-355.

81. McLEAN S. R. Depth-integrated suspended-load calculations. Journal of Hydraulic Engineering, ASCE, 1991, 117, No. 11, 1440-1458.

82. McLeAN S. R. On the calculation of suspended load for non-cohesive sediments. Journal of Geophysical Research, $A G U$, 1992, 97, No. C4, 5759-5770.

83. Villaret C. and Trowbridge J. H. Effects of stratification by suspended sediments on turbulent shear flows. Journal of Geophysical Research, 1991, 96, No. C6, 10659-10680.

84. McLean S. R. Stratification effects due to suspended sediments. Proceedings of an International Symposium on Transport of Suspended Sediments and its Mathematical Modelling, Florence, September 1991, pp. 145-164.

85. WeI L. Governing equations for mathematical river modelling. In River Modelling (XIE J. (ed.)). China Water and Power Press, Beijing, 1990, Ch. 1 (in Chinese).

86. PARK I. and JAIN S. C. River-bed profiles with imposed sediment load. Journal of Hydraulic Engineering, ASCE, 1986, 112, No. 4, 267-280.
87. PARK I. and JAIN S. C. Numerical simulation of degradation of alluvial channel bed. Journal of Hydraulic Engineering, ASCE, 1987, 113, No. 7, 845-859.

88. DE VRIES M. Considerations about non-steady bed-load transport in open channels. Proceedings of the 11th International Congress, IAHR, Delft, 1965, 3.8.1-3.8.11.

89. DE VRIES M. River bed variations-aggradation and degradation. Proceedings of an International Seminar on the Hydraulics of Alluvial Streams, IAHR, Delft, 1973, pp. $1-10$.

90. MorRis P. H. and Williams D. J. Relative celerities of mobile bed flows with finite solids concentrations. Journal of Hydraulic Engineering, ASCE, 1996, 122, No. 6, 311-315.

91. Cao Z. and Egashira S. (2000). Conceptual aspects of 1D mathematical models for alluvial rivers. Journal of Hydroscience and Hydraulic Engineering, JSCE, 2000, 18, No. 1, 127-140.

92. CADAM. Concerted Action on Dambreak Modelling. HR Wallingford, 2000, Final Report SR571.

93. JIN M. and FREAD D. L. Dynamic flood routing with explicit and implicit numerical solution schemes. Journal of Hydraulic Engineering, ASCE, 1997, 123, No. 3, 166173.

94. Zoppou C. and RoberTs S. Discussion on: Space-time conservation method applied to Saint Venant equations. Journal of Hydraulic Engineering, ASCE, 1999, 125, No. 8, 891-892.

95. CAo Z. Discussion on: Numerical morphological modelling of open-check dams by Busnelli M. M. et al., Journal of Hydraulic Engineering, ASCE (in press).

96. Cao Z., Day R. and Egashira S. Coupled and decoupled numerical modelling of flow and morphological evolution in alluvial rivers. Journal of Hydraulic Engineering, ASCE, 2002, 128, No. 3, 306-321.

97. Bhallamudi S. M. and Chaudhry M. H. Numerical modelling of aggradation and degradation in alluvial channels. Journal of Hydraulic Engineering, ASCE, 1991, 117, No. 9, 1145-1164.

98. Lane S. N., Bradbrook K. F., Richards K. S., Biron P. A. and RoY A. G. The application of computational fluid dynamics to natural river channels: 3D versus 2D approaches. Geomorphology, 1999, 29, 1-20.

99. Carling P. A., Williams J. J., Golz E. and Kelsey A. D. The morphodynamics of fluvial sand dunes in the River Rhine, near Mainz, Germany. II. Hydrodynamics and sediment transport. Sedimentology, 2000, 47, No. 1, 253278.

100. IAHR Research Agenda and Future Topics of Concern. IAHR, Delft, 1999.

101. JAW S. Y. and Chen C. J. Present status of second-order closure turbulence models. I: overview. Journal of Engineering Mechanics, 1998, 124, No. 5, 485-501.

102. JAW S. Y. and CHEN C. J. Present status of second-order closure turbulence models. II: applications. Journal of Engineering Mechanics, 1998, 124, No. 5, 502-512.

103. DReW D. A. Mathematical modelling of two phase flow. Annual Review of Fluid Mechanics, 1983, 15, 261-291.

104. Villaret C. and Davis A. G. Modelling sediment-turbulent flow interactions. Applied Mechanics Review, ASME, 1995, 48, No. 9, 601-609.

105. Shi J., Thomas T. G. and Williams J. J. R. Large-eddy 
simulation of flow in a rectangular open channel. Journal of Hydraulic Research, IAHR, 1999, 37, No. 3, 345-361.

106. HiRT C. W. and Nichols B. D. Volume of Fluid (VOF) method for the dynamics of free boundaries. Journal of Computational Physics, 1981, 39, 201-225.

107. Li B. and Fleming C. A. 3D model of Navier-Stokes equations for water waves. Journal of Water, Port, Coastal and Ocean Engineering, ASCE, 2001, 127, No. 1, 16-25.

108. DARBY S. E. Modelling width adjustment in straight alluvial channels. Hydrological Processes, 1998, 12, 1299-1321.

109. Darby S. E. and Thorne C. R. Prediction of tension crack location and riverbank hazards along destabilised chan- nels. Earth Surface Processes and Landforms, 1994, 19, 233-246.

110. Darby S. E. and Thorne C. R. Numerical simulation of widening and bed deformation in straight sand-bed rivers. I: Model development. Journal of Hydraulic Engineering, ASCE, 1996, 122, No. 4, 184-193.

111. Darby S. E. and Thorne C. R. Development and testing of a stability analysis for cohesive riverbanks. Journal of Hydraulic Engineering, ASCE, 1996, 122, No. 8, 443454.

112. Darby S. E., Thorne C. R. and Simon A. Numerical simulation of widening and bed deformation in straight sand-bed rivers. II: Model evaluation. Journal of Hydraulic Engineering, ASCE, 1996, 122, No. 4, 194-202.

Please email, fax or post your discussion contributions to the secretary by I March 2003: email: lyn.richards@ice.org.uk; fax: +44 (0)20 7799 1325; or post to Lyn Richards, Journals Department, Institution of Civil Engineers, I-7 Great George Street, London SWIP 3AA. 